\title{
Electricity Savings Due to the Replacement of Fluorescent Lamps with LEDs in Classrooms
}

\author{
Enedir Ghisi ${ }^{1}$, Thaiane Cristina Stahnke Manorov ${ }^{1}$, Lucas Niehuns Antunes ${ }^{1}$ and \\ Liseane Padilha Thives ${ }^{1}$
}

\begin{abstract}
This work aims to evaluate the potential for electricity savings that the replacement of fluorescent lamps with LEDs can provide. The study was carried out in the classrooms of the Federal University of Santa Catarina. It was found that $65 \%$ of the classrooms had adequate illuminance for classes during the daytime period, but none had an adequate illuminance for the night period. Due to the need to improve lighting and with the aim of reducing energy consumption, a new lighting system was developed using the Dialux software. The new system reduces the installed power of the classrooms in $45.5 \%$. The payback of the investment is 8.6 years, less than the lifespan of the LED lamps, estimated in approximately ten years. This makes the LED system viable both technically and economically. Considering a new building, the system with LED lamps in classrooms would generate savings of approximately $\mathrm{R} \$ 80,000$ over a period of ten years compared to the system with fluorescent lamps. Therefore, although the initial investment is greater, the LED system is economically feasible and could allow for improvements in the lighting system of the classrooms in the Federal University of Santa Catarina.
\end{abstract}

Keywords: Energy efficiency, lighting, LED, classrooms, Dialux.

\section{Introduction}

At the beginning of the 19th century, low and high pressure discharge lamps were developed. Low-pressure bulbs include fluorescent lamps, which were developed in 1926. However, these bulbs faced problems such as the need for better manufacturing facilities and high acquisition costs. This problem has been decreased over the years as the use of such bulbs increased. In the 1960s, Light Emitting Diodes (LEDs) were developed, i.e., semiconductor devices that allow the passage of current in only one direction. Such polarization results in the emission of light. At the beginning they were only used in electronic devices and indicative lighting, but with the advances in research it became possible to develop increasingly powerful and efficient LEDs. This fact combined with the discovery of the white light emission allowed their use, with high efficiency, for illumination of environments (Bullough, 2003).

The current efficiency of LEDs (up to $130 \mathrm{~lm} / \mathrm{W}$ ) is expected to increase in the coming years to reach its maximum efficiency $(200 \mathrm{~lm} / \mathrm{W})$ in the coming decades (EIA, 2014). In addition to the higher efficiency of LED bulbs, their directional light beam and welldefined position of luminaires improve light utilization by directing it only where it is needed thus decreasing energy consumption. The difference between the LED light beam compared to the traditional sources is one of the determining factors in the efficiency of systems using such technology (Krames, Shchekin, Mueller-Mach, Mueller, Zhou, Harbers \& Craford, 2007). 
Many LED manufacturers claim that it is possible to achieve savings of up to $50 \%$ when replacing T8 fluorescent lamps with linear LED bulbs. Depending on the LED directional beam, some manufacturers state that luminaires with LED achieve equal or greater levels of illumination in the task area, even if the LED luminous flux is considerably lower. However, they do not mention that the distribution of illuminance levels will be impaired; and such information cannot be omitted or forgotten when planning the new lighting system (Ryckaert, Smet, Roelandts, Van Gils \& Hanselaer, 2012).

Nardelli, Deuschle, Azevedo, Pessoa and Ghisi (2017) also observed that "the acquisition costs are still higher than those of other lighting systems and the market still offers too many low-quality LEDs. Furthermore, LEDs with inefficient heat dissipation may have high lumen depreciation and, therefore, a shorter lifespan. Despite these limitations, however, LED technology is evolving rapidly and, unlike other light sources, has great potential for improvement and may be the best alternative for lighting in the next few years."

In environments where activities such as reading, drawing and writing are carried out, lighting plays a fundamental role in carrying out such activities. For this reason, it is important that when there is the replacement of lighting fixtures, the level of illuminance and the colour rendering index are maintained or improved.

In this context, it is important to investigate the energy efficiency of lighting systems that aim to replace tubular fluorescent lamps with LEDs. The overall objective of this work is to evaluate the energy-saving potential that lighting systems composed of LED lamps offer compared to systems using tubular fluorescent lamps.

\section{Method}

The study was carried out in 28 classrooms of the Federal University of Santa Catarina (UFSC). All the rooms have the same architectural characteristics, but they have different sizes. First, the current lighting system was evaluated through the measurement of illuminance levels and interviews with students. A survey of the LED lamps available in stores in Florianópolis was also carried out and then a new lighting system using LEDs was proposed. Finally, the economic feasibility of installing the new system was assessed.

\subsection{Assessment of the lighting system}

The current lighting system consists of $32 \mathrm{~W}$ fluorescent lamps, two-lamp luminaires, aluminium reflectors. The system is highly efficient (class "A" in the Brazilian Labelling Programme for Energy Efficiency). The existing lamps have a luminous flux equal to $2350 \mathrm{~lm}$ and a luminous efficiency equal to $73.4 \mathrm{~lm} / \mathrm{W}$, a colour temperature of $4100 \mathrm{~K}$, a lifespan equal to 12000 hours and a colour rendering index equal to 60 . According to NBR 8995-1 (ABNT, 2013), these could not be used in the classrooms because they presented colour rendering index lower than 80. Eq. 1 was used to determine the electricity consumed in each classroom.

$E=P x N \times t$

Where: $E$ is the daily electricity consumption in each classroom $(\mathrm{kWh}) ; P$ is the nominal 
power of each lamp $(\mathrm{kW}) ; N$ is the number of lamps in the classroom; $t$ is the time the lamps are on daily (h).

Eq. 2 provides the annual expenditure on electricity in each classroom.

$C=E x V \times d$

Where: $C$ is the annual expense $(\mathrm{R} \$) ; E$ is the daily electricity consumed in each classroom $(\mathrm{kWh})$; $V$ is the energy tariff per $\mathrm{kWh}(\mathrm{R} \$)$; $d$ is the number of working days in the year.

\subsubsection{Illuminance levels in the classrooms}

The survey of illuminance levels was carried out in fourteen classrooms. The illuminance was measured during the morning, afternoon and evening periods. The daytime measurements occurred over clear sunny days in December 2017. They were performed with the curtains open and the lights off and then on. During the night period measurements were taken with the curtains closed to minimize the influence of outside light and with the lamps on. This way it is possible to quantify the amount of artificial light coming from luminaires and daylighting. The measurements were carried out using a digital luxmeter of the brand Minipa, model MLM-1011 (Fig. 1).

Fig. 1. Portable luxmeter used for measurements.

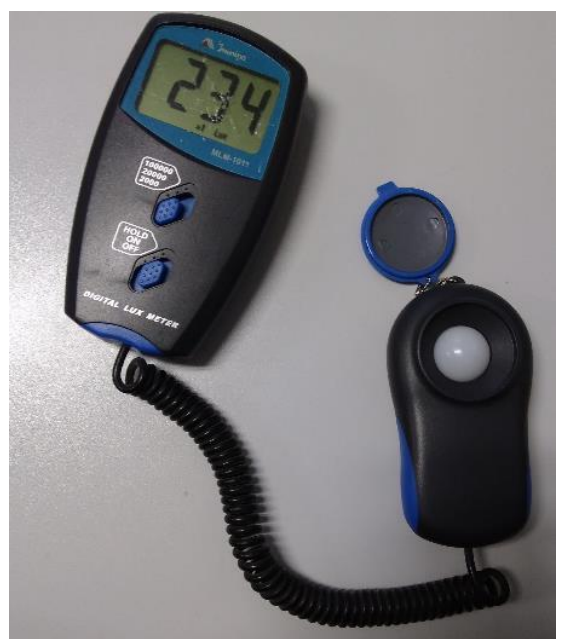

Measurements were performed placing the luxmeter on the working surfaces (in this case, the desks), which have a height of $0.75 \mathrm{~m}$. To determine the number of minimum points required for the measurement of the illuminance levels, it was necessary to determine the room index using Eq. 3. Then, the minimum number of points was estimated using Eq. 4.

$K=\frac{C \times L}{H_{m}(C+L)}$

Where: $K$ is the room index (dimensionless); $C$ is the length of the classroom $(\mathrm{m})$; $L$ is the width of the classroom (m); $H_{m}$ is the height between the working surface and the luminaires $(\mathrm{m})$.

$N=(K+2)^{2}$ 
Where: $N$ is the minimum number of points for measurement of the illuminance level (dimensionless); $K$ is the room index (dimensionless).

\subsubsection{User opinion}

A questionnaire was applied to evaluate the opinion of the students about the current situation of the classrooms in order to improve the lighting system. A pilot study was carried out with six students between 19 and 22 years of age to verify the time of application and possible doubts on the questions.

\subsection{The new lighting system}

The development of a new lighting system was proposed by means of computer simulations using Dialux Evo 8.0. Dialux is a software used for lighting design. Through electronic catalogues provided by manufacturers of lamps and luminaires and data about the rooms, the software provides the quantity and distribution of luminaires to maintain the desired lighting levels. The data about the rooms are: dimensions, surface characteristics, lighting levels to be achieved and depreciation factor.

The simulations were carried out with the objective of proposing another lighting system that would standardize the lighting levels in the classrooms at 300 lux. The modelling of the rooms was done in the programme interface. Simulations were performed for two classrooms (room A and room B) that represent most classrooms at UFSC. The Dialux provides the distribution of the illuminance levels for each classroom.

\subsubsection{LEDs available in local stores}

Characteristics of 23 brands and 188 different types of LEDs (bulb and tubular) were collected. Features surveyed include: power, luminous flux, colour temperature, brand, colour rendering index and light beam aperture angle.

Statistical tests were performed using the SEstatNet platform, and coefficients were obtained for verifying the existence or non-existence of correlations between variables. SEstatNet is an online platform that applies description, estimation, hypothesis testing, and regression models to qualitative and quantitative variables. Mann-Whitney and Spearman tests were used. The characteristics analysed were: luminous efficiency, type of lamp (tubular or bulb), power and colour temperature.

\subsection{Economic analysis}

The implementation of the new system implies initial costs with equipment and manpower for its installation. In order to assess the economic viability, the net present value (NPV) was calculated by means of Eq. 5 .

$N P V=C_{0}+\sum \frac{F_{n}}{(1+i)^{n}}+\sum C \frac{(1+i)^{n}-1}{i x(1+i)^{n}}$

Where: $N P V$ is the net present value $(\mathrm{R} \$) ; F_{n}$ is the cash flow over period $\mathrm{n}(\mathrm{R} \$) ; C_{0}$ is the initial investment of the system; $C$ is the annual electricity cost due to lighting (R\$); $i$ is the inflation rate $(\%) ; n$ is the period considered (year).

Two scenarios were analysed. The first scenario considers a building with a system of fluorescent lamps already installed, which will be replaced. In this case, the payback time will be calculated. The NPV calculation considers the initial value of acquisition of LED 
lamps and luminaires, manpower, and annual electricity and monetary savings over the lifespan of the new system. The annual electricity costs due to lighting, which represents the savings generated by the new system, were estimated by means of Eq. 6 .

$E=\left(\Sigma P_{1}-\Sigma P_{2}\right) x t \times V \times d$

Where: $E$ is the annual electricity savings due to the replacement of lamps (R\$); $\Sigma P_{1}$ is the installed power of existing lamps $(\mathrm{kW}) ; \Sigma P_{2}$ is the total power of the new lamps $(\mathrm{kW})$; $t$ is the usage time per day (h); $V$ is the electricity tariff $(\mathrm{R} \$ / \mathrm{kWh}) ; d$ is the number of operating days per year.

The second scenario considers the case of a building without an installed lighting system such as a new building. In this case, there is no payback time, so the analysis was performed by comparing the two systems to evaluate which is the most feasible. Initial costs include equipment and labour. The time considered in the two cases is the lifespan of the LED, i.e., 25,000 hours. The average lifespan of currently used fluorescent lamps is 12,000 hours, which results in lamp replacement every 4.9 years. In this case the annual cost is determined by means of Eq. 7 .

$C=\Sigma \mathrm{P} x t \times V \times d$

Where: $C$ is the annual electricity cost due to lighting (R\$); $\Sigma P$ is total power of the LED lamps $(\mathrm{kW}) ; t$ is the usage time per day $(\mathrm{h}) ; V$ is the electricity tariff $(\mathrm{R} \$ / \mathrm{kWh}) ; d$ is the number of operating days per year.

\section{Results}

\subsection{Illuminance levels}

Table 1 shows the quantity of rooms and room dimensions. By means of Eq. 4 the number of measurement points for each room was determined. The rooms were divided into approximately equal squares and measurements were taken in the centre of each square. In room A the minimum number of points calculated was 12. For room B the number of points was 18 .

Table 1. Room dimensions

\begin{tabular}{c|c|c|c|c|c}
\hline Room & Quantity of rooms & Length $(\mathrm{m})$ & Width $(\mathrm{m})$ & $H_{m}(\mathrm{~m})$ & Area $\left(\mathrm{m}^{2}\right)$ \\
\hline A & 17 & 7.0 & 7.1 & 2.5 & 50 \\
\hline B & 11 & 11.0 & 7.1 & 2.0 & 78 \\
\hline
\end{tabular}

Illuminance levels at day time (daylight and artificial light at the same time) ranged from 217 lux to 454 lux. Such variation is due to the difference in daylight levels according to solar orientations and also differences of brands, models and age of lamps and luminaires. As a tolerance of up to $10 \%$ below the recommended values is allowed by the Brazilian standard, illuminance levels should be equal to or greater than 270 lux. Average illuminance levels were lower than 270 lux in five rooms and therefore did not comply with NBR 8995-1. When considering only artificial lighting, which is what happens during night classes and on cloudy days, none of the rooms analysed had illuminance levels greater than 270 lux. This makes all rooms inappropriate for school use. These results show that it is necessary to perform a new lighting design to increase the illuminance levels in all classrooms. 


\subsection{User opinion}

Fig. 2 shows the results about the opinion of students on the current lighting system. Most interviewees (85.8\%) are satisfied with the lighting levels in the rooms and only $5.0 \%$ of the respondents said they cannot perform activities such as reading, drawing or writing properly. The visualization of the black board depends on the position of the observer, which may explain why the question had a higher percentage of negative responses than the others, i.e., $25.3 \%$ of respondents said they could not read adequately what was written on the dark board. The lighting of the dark board is very important and should receive as much attention as the lighting levels on the desks. Only $4.8 \%$ of respondents said they noticed and bothered with the brightness of the lamps. The majority $(86.5 \%)$ of respondents stated perceiving, but not bothering with brightness. Only $8.7 \%$ state that the brightness caused by the lamps is unnoticeable. Although $82.6 \%$ of the students said they found the room well lit, $86.7 \%$ of them said they would like the room to be lighter.

Most users are satisfied with the current lighting conditions. However, this does not dispense with the need for changes in lighting to improve the visualization of the black board, to comply with the Brazilian standard and to attend to those who have greater visual difficulties.

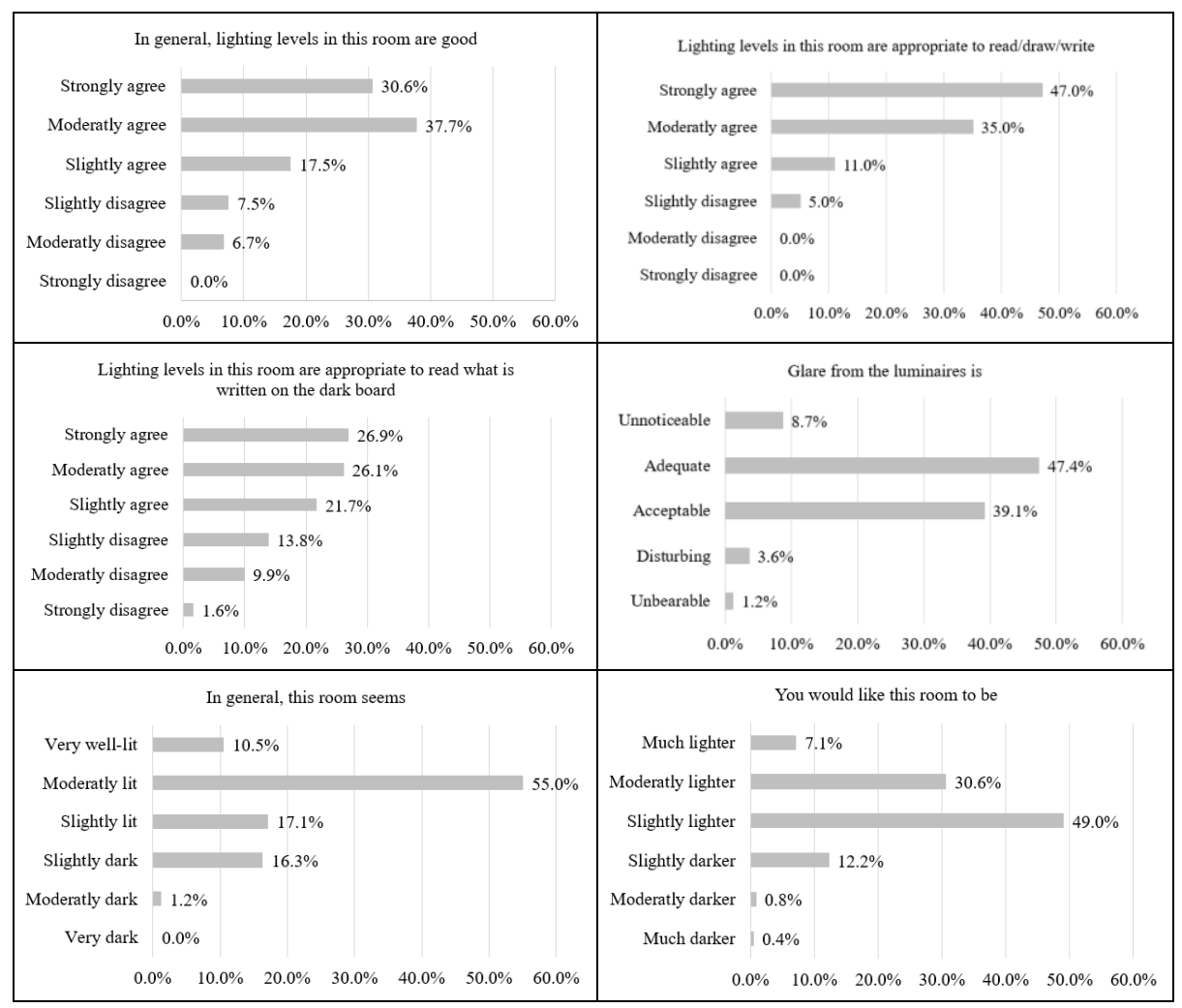

Fig. 2. Opinion of students on the current lighting system. 


\subsection{The new lighting system}

\subsubsection{LEDs available}

Out of the 23 brands and 188 LED lamps analysed, eight presented colour rendering index less than 80 , which is the minimum value recommended by the Brazilian standard. Therefore, those eight were not taken into account. Table 2 shows a summary on the energy efficiency of lamps found in stores in Florianópolis while Table 3 presents a comparison between types of lamps. Out of the 180 LED lamps considered, 37 were tubular $(20.6 \%)$ and 143 were bulbs $(79.4 \%)$.

Table 2. Energy efficiency statistics of lamps found in stores in Florianópolis

\begin{tabular}{l|c}
\hline Average $(\mathrm{lm} / \mathrm{W})$ & 96.7 \\
\hline Standard deviation $(\mathrm{lm} / \mathrm{W})$ & 10.0 \\
\hline Coefficient of variation $(\%)$ & 10.3 \\
\hline Median $(\mathrm{lm} / \mathrm{W})$ & 96.5 \\
\hline Minimum $(\mathrm{lm} / \mathrm{W})$ & 75 \\
\hline Maximum $(\mathrm{lm} / \mathrm{W})$ & 130 \\
\hline
\end{tabular}

Table 3. Comparison between types of lamps found in stores in Florianópolis

\begin{tabular}{l|c|c|c|c|c}
\hline Type of lamp & $\begin{array}{c}\text { Average } \\
\text { efficiency } \\
(\mathrm{lm} / \mathrm{W})\end{array}$ & $\begin{array}{c}\text { Minimum } \\
\text { efficiency } \\
(\mathrm{lm} / \mathrm{W})\end{array}$ & $\begin{array}{c}\text { Maximum } \\
\text { efficiency } \\
(\mathrm{lm} / \mathrm{W})\end{array}$ & $\begin{array}{c}\text { Minimum } \\
\text { luminous flux } \\
(\mathrm{lm})\end{array}$ & $\begin{array}{c}\text { Maximum } \\
\text { luminous flux } \\
(\mathrm{lm})\end{array}$ \\
\hline Bulb & 96.5 & 75 & 130 & 330 & 5000 \\
\hline Tubular & 97.9 & 80 & 111 & 803 & 2000 \\
\hline
\end{tabular}

As for the correlations analysed, it was obtained that there is no correlation between luminous efficiency and type of LED (tubular or bulb); there is no correlation between luminous efficiency and power; there is no correlation between luminous efficiency and colour temperature.

\subsubsection{Computer simulations}

Several simulations were performed considering bulb and tubular LED lamps with $0.60 \mathrm{~m}$ and $1.20 \mathrm{~m}$ in length. The dimensions used for the modelling of the room are shown in Table 1 and the reflectances of the surfaces, considered according to the values suggested by the standard NBR 8995-1, are shown in Table 4.

Table 4. Reflectances considered in the simulations

\begin{tabular}{l|c}
\hline Surface & Reflectance (\%) \\
\hline Wall & 52 \\
\hline Ceiling & 77 \\
\hline Floor & 78 \\
\hline Blackboard & 40 \\
\hline Desks & 50 \\
\hline
\end{tabular}

The depreciation factor used was 0.8 . The work plan considered was the height of the desks, i.e., $0.75 \mathrm{~m}$. The best solution found to meet the criterion of minimum illuminance and distribution of illuminances for both rooms was found for tubular LED 
lamps of $0.6 \mathrm{~m}$ in length. Table 5 shows the technical characteristics of the lamp chosen. Fig. 3 shows the luminous intensity distribution curve for the lamp-luminaire chosen.

Table 5. Technical characteristics of the LED lamp chosen

\begin{tabular}{l|c}
\hline Number of lamps per luminaire & 2 \\
\hline Lamp power (W) & 9 \\
\hline Lamp lifespan (h) & 25,000 \\
\hline Power per luminaire (W) & 18 \\
\hline Colour temperature (K) & 4000 \\
\hline Colour rendering index & 82 \\
\hline Total luminous flux per luminaire $(\mathrm{lm})$ & 2109 \\
\hline Efficiency $(\mathrm{lm} / \mathrm{W})$ & 105.5 \\
\hline
\end{tabular}

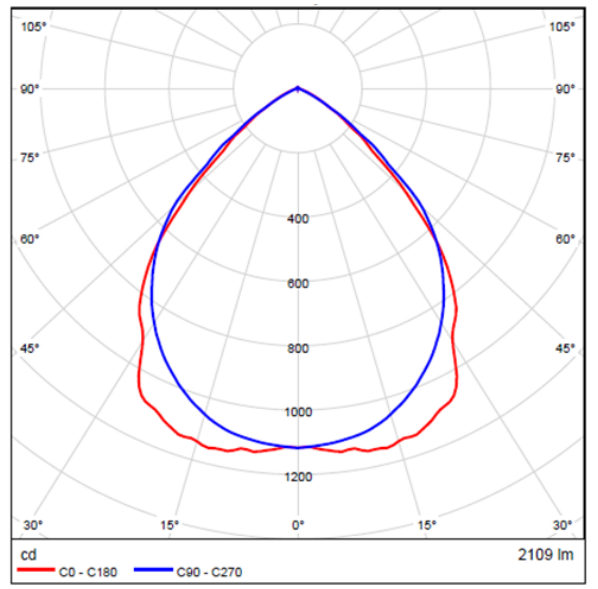

Fig. 3. Luminous intensity distribution curve for the lamp-luminaire assembly chosen.

Figs. 4 and 5 show, respectively, a view and the illuminances on the desk plan of room A obtained from the Dialux software. Table 6 shows a summary of the results obtained from the simulations for rooms $\mathrm{A}$ and $\mathrm{B}$.

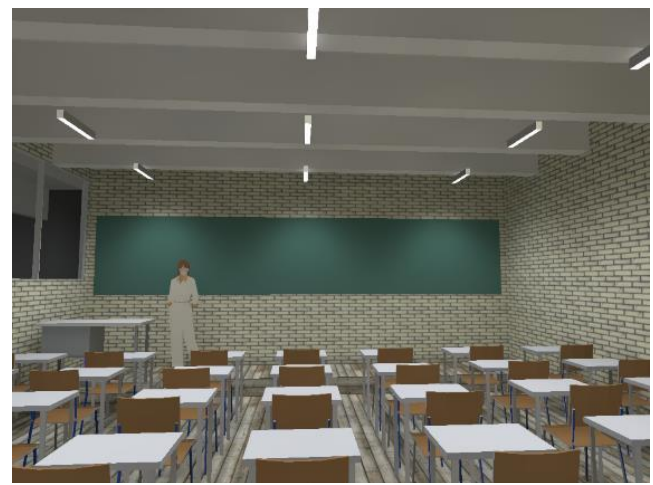

Fig. 4. Internal view of room A obtained from the Dialux software 


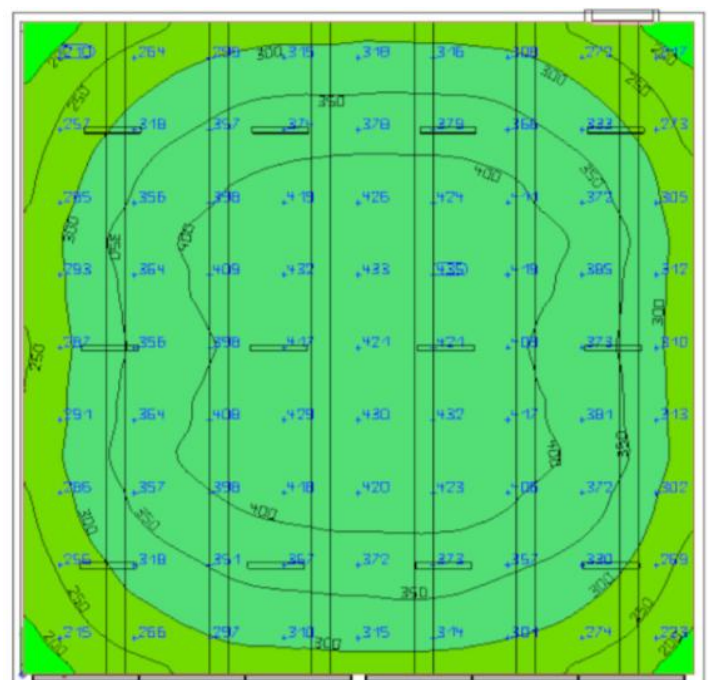

Fig. 5. Illuminances on the desk plan of room A obtained from the Dialux software

Table 6. Summary of results

\begin{tabular}{l|c|c}
\hline Illuminance & Room A & Room B \\
\hline Average (lux) & 355 & 304 \\
\hline Minimum (lux) & 169 & 146 \\
\hline Maximum (lux) & 446 & 411 \\
\hline Minimum/Average & 0.48 & 0.48 \\
\hline Minimum/Maximum & 0.38 & 0.36 \\
\hline
\end{tabular}

The results obtained meet the normative requirements. From the point of view of lighting quality and energy efficiency, the new design is feasible.

\subsection{Economic analysis}

Tables 7 and 8 show the energy consumption and costs for the current and new system, respectively. The total values presented consider all existing rooms (17 rooms A and 11 rooms $\mathrm{B})$.

Table 7. Details about the current system

\begin{tabular}{c|c|c|c|c|c|c}
\hline Room & $\begin{array}{c}\text { Number of } \\
\text { lamps }\end{array}$ & $\begin{array}{c}\text { Installed } \\
\text { power }(\mathrm{W})\end{array}$ & $\begin{array}{c}\text { Lighting power } \\
\text { density }\left(\mathrm{W} / \mathrm{m}^{2}\right)\end{array}$ & $\begin{array}{c}\text { Daily consumption } \\
(\mathrm{kWh})\end{array}$ & $\begin{array}{c}\text { Monthly } \\
\text { costs }(\mathrm{R} \$)\end{array}$ & $\begin{array}{c}\text { Annual costs } \\
(\mathrm{R} \$)\end{array}$ \\
\hline $\mathrm{A}$ & 12 & 384 & 7.68 & 4.608 & 59.84 & 557.58 \\
\hline B & 16 & 512 & 6.83 & 6.144 & 79.75 & 742.63 \\
\hline Total & 380 & 1708 & 7.12 & 145.920 & $1,894.53$ & $17,647.79$ \\
\hline
\end{tabular}

Table 8. Details about the new system

\begin{tabular}{c|c|c|c|c|c|c}
\hline Room & $\begin{array}{c}\text { Number of } \\
\text { lamps }\end{array}$ & $\begin{array}{c}\text { Installed } \\
\text { power }(\mathrm{W})\end{array}$ & $\begin{array}{c}\text { Lighting power } \\
\text { density }\left(\mathrm{W} / \mathrm{m}^{2}\right)\end{array}$ & $\begin{array}{c}\text { Daily consumption } \\
(\mathrm{kWh})\end{array}$ & $\begin{array}{c}\text { Monthly } \\
\text { costs }(\mathrm{R} \$)\end{array}$ & $\begin{array}{c}\text { Annual costs } \\
(\mathrm{R} \$)\end{array}$ \\
\hline A & 24 & 216 & 4.32 & 2.592 & 33.64 & 313.50 \\
\hline B & 30 & 270 & 3.46 & 3.240 & 42.05 & 391.88 \\
\hline Total & 369 & 6.642 & 3.89 & 79.704 & $1,034.43$ & $9,640.18$ \\
\hline
\end{tabular}


It can be seen that the daily electricity consumption due to lighting would be reduced from $145.92 \mathrm{kWh}$ to $79.70 \mathrm{kWh}$ per day, while the monthly costs would be reduced from $\mathrm{R} \$ 1,894.53$ to $\mathrm{R} \$ 1,034.43$, resulting in savings equal to $\mathrm{R} \$ 8,007.61$ per year. Therefore, the new lighting system would allow for electricity savings equal to $45.4 \%$.

To calculate the payback time of the investment it is necessary to estimate the initial costs. For the first scenario, a labour cost of $\mathrm{R} \$ 4,000.00$ was considered, which includes the removal of existing luminaires, light bulbs and ballasts, and the installation of 369 luminaires and 738 LED lamps and the necessary electrical wiring. The LED lamps cost $\mathrm{R} \$ 32.60$ and the new luminaires cost $\mathrm{R} \$ 82.90$. The total cost resulted in $\mathrm{R} \$ 58,648.90$.

In the second scenario, a labour cost of $\mathrm{R} \$ 3,000.00$ was considered, which includes the installation and electrical wiring, luminaires, lamps and ballasts for fluorescent lamps. The cost considered for fluorescent lamps and ballasts was the cost paid by UFSC in 2017 corrected according to inflation rates. The cost considered for the luminaire was the lowest found in the local market, i.e., $\mathrm{R} \$ 72.40$. For the system using LED the costs already described for the first scenario were used.

For the application of Eqs. 5, 6 and 7 the average time of use of the classrooms was considered, i.e., 10 hours a day and 200 days a year. The electricity tariff used to calculate monthly expenses was taken as $\mathrm{R} \$ 0.59$ per $\mathrm{kWh}$ as obtained from UFSC for the first quarter of 2018 (UFSC SUSTENTÁVEL, 2018). The interest rate adopted was based on accumulated inflation over the last 12 months (4.48\% per year), based on July 2018 (IBGE, 2018).

The lifespan of the LED lamps is 25,000 hours; and for the existing fluorescent lamps it is 12,000 hours. Thus, the fluorescent lamps should work for 4.9 years and LED lamps for 10.2 years. The payback time, calculated using Eq. 5 for the first scenario was 8.6 years. Payback is shorter than the lifespan of the system, so the replacement of the actual system with a LED system is economically feasible.

For the second scenario the NPV was calculated for both systems. For the fluorescentlamp system the initial investment includes the purchase of 380 lamps, 190 ballasts and 190 luminaires plus labour, totalling $\mathrm{R} \$ 20,887.03$. Over the analysis time, two lamp replacements will be required. The NPV calculated using Eq. 5 resulted in R\$ 165,575.04. For the system using LED lamps the initial investment includes the same variables of the first scenario, changing only the cost with labour, totalling $\mathrm{R} \$ 57,648.90$. The NPV calculated by means of Eq. 5 resulted in R $\$-135,215.66$. Because of the greater NPV, the system with LED lamps is the most viable. Although the LED system has a higher initial cost it provides savings of $\mathrm{R} \$ 30,359.38$ over the lifespan compared to the fluorescent-lamp system.

\section{Conclusion}

This work aimed to analyse the classroom lighting system of the Federal University of Santa Catarina and propose solutions for energy savings. In the school context, lighting is essential for performing tasks properly. For this reason, the purpose of this work was not only to develop another lighting system to reduce energy consumption, but also to improve the quality of lighting.

Through the measurements of illuminance levels in the classrooms it was found that the 
lighting could be improved. Therefore, it was decided to evaluate the potential for energy savings by replacing the actual fluorescent lamps with LED lamps.

Considering the actual system, average illuminances were lower than the required illuminance (300 lux) in several classrooms. On the other hand, the LED-lamp system would allow average illuminance in the classrooms greater than or equal to 304 lux, in addition to providing better distribution of illuminances.

Regarding the energy performance of the systems, although the system with LEDs contained a greater number of lamp-luminaire assemblies, its power density was lower, i.e., $3.89 \mathrm{~W} / \mathrm{m}^{2}$, while $7.12 \mathrm{~W} / \mathrm{m}^{2}$ with fluorescent lamps. Annual expenses would decrease from $\mathrm{R} \$ 17,647.79$ to $\mathrm{R} \$ 9,640.18$. The electricity consumption would decrease $45.5 \%$.

The use of LED lamps has shown to be able to contribute to energy and environmental issues and, if used in a large scale, can reduce the impacts generated by the use of electricity in lighting systems.

\section{References}

ABNT Associação Brasileira de Normas Técnicas (2013) NBR 8995-1 Iluminação em ambiente de trabalho - Parte 1: Interior [NBR 8995-1 Lighting in working spaces - Part 1: Interior7. Rio de Janeiro, in Portuguese.

Bullough, J. D. (2003) Lighting Answers: LED Lighting Systems. National Lighting Product Information Program, Lighting Research Center, Rensselaer Polytechnic Institute. vol. 7.

EIA (2014). LED Bulb efficiency expected to continue improving as cost declines. Available at <https://www.eia.gov/todayinenergy/detail.php?id=15471>, Accessed 8 May 2018.

IBGE (2018). IPCA foi de 0,33\% em julbo [IPCA was $0.33 \%$ in July]. Available at $<$ https://agenciadenoticias.ibge.gov.br/agencia-sala-de-imprensa/2013-agencia-denoticias/releases/22093-ipca-foi-de-0-33-em-julho>, Accessed 13 August 2018, in Portuguese.

Krames, M. R., Shchekin, O. B., Mueller-Mach, R., Mueller, G. O., Zhou, L., Harbers, G., \& Craford M. G. (2007) Status and Future of High-Power Light-Emitting Diodes for Solid-State Lighting. Journal of Display Technology, 3(2), 160-175.

Nardelli, A., Deuschle, E., Azevedo, L. D., Pessoa, J. L. N., \& Ghisi, E. (2017) Assessment of Light Emitting Diodes technology for general lighting: A critical review. Renewable and Sustainable Energy Reviews, $75,368-379$.

Ryckaert, W. R., Smet, K. A. G., Roelandts, I. A. A., Van Gils, M., \& Hanselaer P. (2012) Linear LED tubes versus fluorescent lamps: An evaluation. Energy and Buildings, 49, 429-436.

UFSC SUSTENTÁVEL (2018). Eficiência Energética [Energy efficiency]. Available at $<$ http://ufscsustentavel.ufsc.br/eficiencia-energetica>, Accessed 13 August 2018, in Portuguese. 